\title{
Efeito da temperatura e do tempo de imersão da etapa de encharcamento sobre a cor dos grãos de arroz parboilizado de cultivares de terras altas
}

\section{Effect of temperature and time immersion of stage soaking on color grains of upland rice parboiled cultivars}

\author{
Flávia Araújo da Fonseca ${ }^{*}$; Manoel Soares Soares Júnior²; Márcio Caliari²; \\ Diva Mendonça Garcia ${ }^{3}$; Priscila Zaczuk Bassinello; Eduardo da Costa Eifert ${ }^{4}$
}

\section{Resumo}

A parboilização consiste no tratamento hidrotérmico do arroz em casca antes do beneficiamento. $\mathrm{O}$ objetivo deste estudo foi avaliar a influência das variáveis temperatura e tempo de imersão da etapa de encharcamento sobre a cor dos grãos parboilizados de cultivares de arroz de terras altas (BRS Primavera e BRS Sertaneja). Utilizou-se um delineamento composto central rotacional (DCCR), que inclui um fatorial completo $2^{2}$, mais três repetições no ponto central e quatro pontos axiais, totalizando onze tratamentos. Considerou-se para seleção das condições hidrotérmicas, o critério de absorção de água na faixa de $28 \%$ - 32\%. Nas condições extremas do encharcamento (elevada temperatura e tempo de imersão) observou-se, em geral, que os grãos de arroz parboilizado apresentaram maior diferença de cor em relação as amostras dos grãos de arroz branco. Portanto, o emprego de temperaturas abaixo de $65^{\circ} \mathrm{C}$ durante o encharcamento tende a resultar em grãos com coloração menos intensa. Após a parboilização sob diferentes condições de temperatura e tempo de encharcamento, a variação de cor $\left(\Delta \mathrm{E}^{*}\right)$ é maior na cv. BRS Sertaneja. Pode-se produzir grãos com diferentes tonalidades, dependendo das condições de processamento utilizadas. A escolha vai depender da aplicação a que se destina ou dos produtos em que serão empregados.

Palavras-chave: Oryza sativa L, tratamento hidrotérmico, análises físicas

\begin{abstract}
The parboiling is the hydrothermal treatment of paddy before processing. The objective of this study was to evaluate the influence of the temperature and immersion time step of soaking (independent variables) on the color of the grain parboiled (dependent variable) cultivars of upland rice (BRS Primavera and BRS Sertaneja). A central composite rotational design (DCCR) was used, which includes a $2^{2}$ full factorial, three replicates at the center point and four axial points, making eleven treatments. It was considered for the selection of hydrothermal conditions to be studied, the criterion of water absorption in the age group from $28 \%-32 \%$. In extreme conditions of soaking (high temperature and immersion time) was observed in general that the grains of parboiled rice had higher color difference for
\end{abstract}

\footnotetext{
${ }^{1}$ Prof ${ }^{a}$ no Senai/GO, atua em programas de qualidade nutricional e tecnológica de arroz parboilizado, Mestre em Ciência e Tecnologia de Alimentos, Universidade Federal de Goiás. E-mail: flavia.eaufg@gmail.com

${ }^{2}$ Prof. Adjunto, Universidade Federal de Goiás. Setor de Engenharia de Alimentos, Escola de Agronomia e Engenharia de Alimentos, Universidade Federal de Goiás, Caixa Postal 131, CEP 74.001-970, Goiânia, GO. E-mail: manoel@agro.ufg.br; macaliari@ig.com.br

${ }^{3}$ Prof ${ }^{a}$ do Instituto Federal de Educação Tecnológica de Goiás, Urutaí, GO. E-mail: diva.mg@gmail.com

${ }^{4}$ Pesquisador III e Pesquisador A, Embrapa Arroz e Feijão, Caixa Postal 179, CEP 75.375-000, Santo Antônio de Goiás, GO. E-mail: pzbassin@cnpaf.embrapa.br; eifert@cnpaf.embrapa.br

* Autor para correspondência
} 
the samples of grains of white rice. Therefore, the use of temperatures below $65{ }^{\circ} \mathrm{C}$ during the soaking tend to have grains with milder browning. After parboiling under different conditions of temperature and time of soaking, the change of color $\left(\Delta \mathrm{E}^{*}\right)$ was greater in $\mathrm{cv}$. BRS Sertaneja. It is possible to produce grains with different shades, depending on the conditions used. The choice will depend on the application that is intended or products in wich the rice will be employed.

Key words: Oryza sativa L, hydrothermal treatment, physical analysis

\section{Introdução}

No Brasil, o arroz (Oriza sativa L.) possui grande importância econômica e social, por ser um produto básico da alimentação da população (FERREIRA et al., 2009). O arroz de sequeiro, hoje denominado de terras altas, ganhou destaque nos sistemas de produção usados na abertura dos Cerrados, para a implantação de pastagens (GUIMARÃES; STONE, 2004), graças à disponibilidade de novas cultivares de arroz de terras altas, com ótima qualidade de grãos (BRESEGHELLO; CASTRO; MORAIS, 1998).

Parboilização é um tratamento hidrotérmico aplicado ao arroz cru, que possui três etapas: encharcamento, vaporização e secagem. Durante esse tratamento, ocorre a gelatinização do amido, que passa da forma cristalina para amorfa, tornando o endosperma translúcido e com textura mais compacta (AMATO; ELIAS, 2005). Por isso, o grão adquire mais força para resistir ao polimento, quebrando menos durante o beneficiamento, além de reduzir a remoção excessiva de compostos importantes do ponto de vista nutricional presentes no farelo do grão (SRIDHAR; MANOHAR, 2003). Além disso, o produto parboilizado torna-se mais solto quando cozido, rende mais na panela, requer menos óleo no cozimento, pode ser reaquecido diversas vezes, mantendo suas propriedades nutritivas, é menos susceptível ao ataque de insetos e conserva-se por mais tempo, devido o efeito de pasteurização enzimática e microbiológica (BASSINELLO; CASTRO, 2004).

Por estas razões, o arroz parboilizado tem, em nível internacional, o respaldo de instituições como a Organização das Nações Unidas para a Agricultura e Alimentação (FAO) e a Organização Mundial de
Saúde (OMS), representando aproximadamente $50 \%$ da produção de arroz mundial, atingindo já cerca de $20 \%$ no Brasil e isso motiva a sua adoção em programas nacionais de saúde, onde o consumo é dirigido a creches, hospitais e estabelecimentos para idosos (AMATO; SILVEIRA FILHO, 1995; CHOUDHURY, 1991).

No arroz parboilizado, assim como na maioria dos alimentos, a cor ocupa um lugar de destaque entre os atributos sensoriais, em razão de causar o primeiro impacto no observador do produto (AMATO et al., 1990). Estabelecido o hábito de consumo do arroz branco, a demanda pelo arroz parboilizado, que passou a ter consumo significativo no ocidente após a II Grande Guerra, teve que acompanhar a preferência pelas cores mais brandas (AMATO et al., 1990). Como consequência do processo hidrotérmico, o arroz parboilizado apresenta uma cor amarelo-pálida, grãos com textura rígida, mesmo após o cozimento, e um sabor característico, embora a extensão de tais alterações dependa da severidade do tratamento térmico aplicado (HEINEMANN; BEHRENS; LANFERMARQUEZ, 2006).

Há uma sequência de causas, em série, capazes de serem responsáveis pela alteração da cor no processo de parboilização. Umas dessas causas precedem a industrialização, remontando à própria natureza do grão, onde pigmentos vermelhos e amarelos dissolvidos da casca e da camada do farelo podem contribuir parcialmente, tanto por difusão até o endosperma quanto pela absorção por este após a abertura da casca. Cultivares de arroz com casca de coloração mais escura resultam, geralmente, num produto mais escurecido (amarelo-claro ou âmbar) após o processo de parboilização, o que prejudica 
a aparência e interfere na aceitação para consumo, quando comparado com o produto mais claro e atrativo (LAMBERTS et al., 2006a, VIEIRA, 2004).

A principal causa atribuída a coloração final do produto está vinculada à composição do arroz e condições inerentes ao tratamento hidrotérmico. Trata-se do escurecimento nãoenzimático ocasionado por reações químicas do tipo Maillard, tendo como causas o nível relativamente alto de açúcares redutores e aminoácidos, em presença de condições adequadas à reação (ALI; BHATTACHARYA, 1976). Como resultado surgem as melanoidinas, de pigmentação marrom, sendo a reação mais intensa em função da concentração de açúcares, das temperaturas mais altas (FONSECA et al., 1983) e do longo tempo de encharcamento (DILLAHUNTY; SIEBENMORGEN; MAUROMOUSTAKOS, 2001). O efeito mais importante nesse processo é a temperatura de encharcamento, podendo ocorrer o splitting, mais intenso acima de $70{ }^{\circ} \mathrm{C}$, com a consequente absorção pelo endosperma dos pigmentos (AMATO et al., 1990).

$\mathrm{O} \mathrm{pH}$ da água de encharcamento afetou a cor do arroz parboilizado, ocorrendo maior alteração da cor do produto em $\mathrm{pH}$ próximo a 4,5 , em função da aceleração das reações enzimáticas responsáveis pela hidrólise do amido e de proteínas. Além das condições de parboilização, o grau de polimento também afeta a cor do arroz, pois a camada residual de farelo resulta em arroz mais escuro (LAMBERTS et al., 2006a). Pesquisas da International Rice Research Institute (IRRI) demonstram que grãos de cultivares de arroz com alto teor protéico e de cinzas, devido a concentração de ferro e manganês e ainda, pelas vitaminas do complexo $\mathrm{B}$, se apresentam menos brancos após o cozimento. O Departamento de Agricultura dos EUA (USDA), também correlaciona cor mais escura com concentração de lipídios, pois, estes compostos, assim como as proteínas se concentram nas camadas externas do grão (AMATO; CARVALHO; SILVEIRA FILHO, 2002).
Na parboilização, as causas da variação da cor são inúmeras, podendo-se citar, como exemplos, algumas interações entre os fatores envolvidos no encharcamento, como, utilização de água turva (devido a argilas em suspensão) associada à tendência do grão em abrir a casca, e coloração da casca de determinada variedade de arroz frente a excessos de tempo de imersão e da temperatura aplicada durante essa operação unitária (AMATO; CARVALHO; SILVEIRA FILHO, 2002).

O objetivo deste trabalho é avaliar a influência das variáveis temperatura e tempo de imersão da etapa de encharcamento sobre a cor dos grãos parboilizados de dois cultivares de arroz de terras altas ("BRS Primavera" e "BRS Sertaneja").

\section{Material e Métodos}

Os experimentos foram realizados no Laboratório de Tecnologia de Alimentos da Embrapa Arroz e Feijão - Santo Antônio de GoiásGO e no Laboratório de Análises Físico-Químicas de Alimentos da Escola de Agronomia e Engenharia de Alimentos da Universidade Federal de Goiás Goiânia.

As cultivares de arroz utilizadas foram a BRS Primavera e BRS Sertaneja, produzidas sob o sistema de cultivo de terras altas (sequeiro) e colhidas entre abril e maio de 2007, na Fazenda Capivara, situada no município de Santo Antônio de Goiás-GO.

$\mathrm{O}$ arroz foi colhido manualmente com teor de umidade de $20 \%$ - $24 \%$ para a cv. BRS Primavera e de $15-23 \%$ de umidade para a cv. BRS Sertaneja. Após a colheita, foi realizada a secagem natural, até os grãos atingirem $13 \%$ de umidade, sendo esta estimada utilizando-se o método dielétrico, com auxílio do determinador de umidade Grainer II PM-300. Para armazenamento, o arroz em casca foi acondicionado em sacos de polipropileno, mantidos em câmara fria sob umidade relativa do ar ao redor de $60 \%$ e temperatura de $27^{\circ} \mathrm{C}$, para estabelecimento de equilíbrio higroscópico do grão em $13 \%$ de umidade. 
Os parâmetros de temperatura e tempo de encharcamento, para definição do delineamento experimental para estudo dos aspectos de qualidade do arroz parboilizado das duas cultivares foram estabelecidos com base nos dados obtidos das isotermas de absorção de água, determinadas de acordo com a metodologia desenvolvida por Elias (1998), que possui duas etapas. Na primeira, as amostras de arroz em casca foram limpas manualmente para eliminação de impurezas e matérias estranhas. Posteriormente, foram colocadas em béqueres de plástico, contendo água potável a temperatura ambiente, agitadas e deixadas em repouso, por $20 \mathrm{seg}$, até separação e eliminação dos grãos imaturos, que flutuaram na superfície da água. Na segunda etapa, os grãos selecionados foram colocados em béqueres de vidro de $2 \mathrm{~L}$, previamente identificados, numa relação de peso de grãos e água de 1:1,6, e deixados em banho-maria (marca Fisatom, modelo 577; marca Marconi, modelo MA 470). Os grãos foram submetidos a tempos de encharcamento entre $60 \mathrm{~min}-720 \mathrm{~min}$ e em temperaturas da água de $60 \pm 1{ }^{\circ} \mathrm{C}, 65 \pm 1^{\circ} \mathrm{C}$ e $70 \pm 1{ }^{\circ} \mathrm{C}$, controladas por um termostato digital. Esta faixa de temperatura foi escolhida, pois, de acordo com estudos já realizados com outras cultivares, a temperatura mais adequada para a etapa de encharcamento é aquela pouco abaixo da faixa de temperatura de gelatinização do amido de arroz $\left(62{ }^{\circ} \mathrm{C}-68{ }^{\circ} \mathrm{C}\right)$. Para o tempo foi realizado um ensaio extrapolativo, uma vez que longos períodos não são compensativos economicamente e para a qualidade do grão. Para que a temperatura no início do encharcamento estivesse de acordo com os valores citados anteriormente, foi necessário calcular qual deveria ser a temperatura da água quando o arroz em casca fosse adicionado ao béquer (AMATO; CARVALHO; SILVEIRA FILHO, 2002). Para cada temperatura estudada, cerca de $2 \mathrm{~g}$ de amostras, em triplicata, foram retiradas do banho de imersão, a cada $60 \mathrm{~min}$, num tempo total de 720 min, totalizando trinta e seis amostras por cultivar. Logo após escorreu-se e removeu-se o excesso de água dos grãos com papel toalha, pesou-se $\left(\mathrm{T}_{\mathrm{i}}\right)$ e secou-se os mesmos em estufa retilínea de bandejas com circulação forçada de ar (marca Nova ética, modelo NE-1527), a $105^{\circ} \mathrm{C}$, até peso constante e pesou-se novamente $\left(\mathrm{T}_{\mathrm{f}}\right)$ para o cálculo da absorção efetiva de água (Eq. 1).

Absorção de água $(\%)=\frac{\left(M_{U}-M_{S}\right)}{M_{U}} \cdot 100 \quad$ (Eq. 1)

Onde:

$\mathrm{M}_{\mathrm{U}-}$ Massa úmida $(\mathrm{g})$ no tempo $\mathrm{T}_{\mathrm{i}}$

$\mathrm{M}_{\mathrm{S}}$ - Massa seca $(\mathrm{g})$ da amostra no tempo $\mathrm{T}_{\mathrm{f}}$

Considerou-se para seleção das condições hidrotérmicas a serem utilizadas no delineamento experimental, o critério de absorção de água de $28 \%$ - 32\%, pois segundo Amato, Carvalho e Silveira Filho (2002), a umidade próxima de 30\% é indispensável para a completa gelatinização do amido do endosperma do grão de arroz. Após a definição das variáveis tempo e temperatura de encharcamento para cada cultivar, utilizou-se o delineamento composto central rotacional, que inclui um fatorial completo $2^{2}$, três repetições no ponto central e quatro pontos axiais, totalizando onze ensaios para cada cultivar, que foram conduzidos de maneira aleatória (RODRIGUES; IEMMA, 2005). Os níveis codificados e originais reais da temperatura da água e do tempo de imersão na água para cada cultivar estão representados nas Tabelas 1 e 2 .

Em um béquer de vidro com volume de $2 \mathrm{~L}$ foram colocados cerca de $400 \mathrm{~g}$ de arroz em casca e $640 \mathrm{~mL}$ de água potável $(1: 1,6)$ com temperatura previamente definida. $\mathrm{O}$ béquer contendo a amostra foi inserido em um banho com água aquecida em uma das temperaturas definidas para o estudo (58 ${ }^{\circ} \mathrm{C}, 60{ }^{\circ} \mathrm{C}, 65^{\circ} \mathrm{C}, 70^{\circ} \mathrm{C}$ e $72^{\circ} \mathrm{C}$ ), conforme Tabelas 1 e 2, para as cvs. BRS Primavera e BRS Sertaneja, respectivamente. Este béquer foi coberto com papel alumínio para evitar possíveis perdas de calor e quedas de sujidades ou mesmo de água condensada na tampa do banho. 
Cada amostra de arroz encharcado, obtida no ensaio de encharcamento, foi colocada novamente em béquer de vidro com volume de 2 L, coberto com papel alumínio, antes de ser submetida a vaporização. Em seguida as amostras de arroz úmido foram autoclavadas por $10 \mathrm{~min}$., a $120{ }^{\circ} \mathrm{C}$ e $1,0 \mathrm{kgf} / \mathrm{cm}^{2}$ de pressão, em autoclave vertical (Marca Phoenix, modelo AV75; marca Prismatec, modelo CS-50). As amostras autoclavadas foram espalhadas em bandeja de aço inox ou bandeja de plástico para resfriarem por $30 \mathrm{~min}$ antes da etapa de secagem.

As amostras autoclavadas foram colocadas em bandejas de polipropileno e submetidas à secagem em estufa retilínea de bandejas com circulação forçada de ar (marca Nova Ética, modelo NE-1527), à temperatura de $40{ }^{\circ} \mathrm{C}$, por um período de $2 \mathrm{~h}-3 \mathrm{~h}$, até atingir $17 \%-18 \%$ de umidade. A cada $20 \mathrm{~min}$ durante este período, as amostras foram revolvidas manualmente, para facilitar a perda uniforme de umidade dos grãos. Quando as amostras atingiram a referida faixa de umidade, o processo de secagem foi interrompido por um período de 24 a $48 \mathrm{~h}$, para que houvesse a dissipação natural do calor. Assim, amostras mantidas a temperatura ambiente e umidade relativa do ar 43,35\% (média referente ao mês de agosto e setembro / 2008) atingiram $13 \%$ de umidade. Em seguida as amostras foram submetidas ao beneficiamento.

O beneficiamento foi realizado após $24 \mathrm{~h}$ do processo de secagem, para que a temperatura do arroz estabilizasse em equilíbrio com a temperatura do ambiente, e os grãos se tornassem endurecidos. As amostras foram descascadas em equipamento marca Satake, modelo IHU. Em seguida, foram submetidas ao polimento em equipamento da marca Grainman, modelo 60-230-60-2AT, durante $1 \mathrm{~min}$, sendo ajustado para evitar a quebra dos grãos e a retirada inadequada do pericarpo, perisperma e a camada de células aleurônicas (farelo). As amostras beneficiadas foram armazenadas sob refrigeração $\left(5^{\circ} \mathrm{C}\right)$, em sacos plásticos de polietileno de baixa densidade (PEBD) (embalagem primária) e acondicionados em potes brancos de polipropileno (embalagem secundária), até o momento das análises.

A coloração dos grãos de arroz parboilizado foi determinada em colorímetro (Hunter lab, Color Quest II), sendo feitas três leituras na amostra de cada experimento. Os parâmetros operacionais utilizados durante a análise foram: ângulo $10^{\circ}$, iluminante $\mathrm{D}_{65}$ e modo de calibração RSIN. Os resultados foram apresentados utilizando o sistema CIELAB, que são as médias dos valores de: $\mathrm{L}^{*}, \mathrm{a}^{*}, \mathrm{~b}^{*}$ (medidos) e $\Delta \mathrm{E}$, calculado pela equação 2 (MINOLTA, 1994). O padrão usado neste trabalho foi a leitura do grão de arroz branco.

$$
\Delta \mathrm{E}=\sqrt{\left(\Delta \mathrm{L}^{*}\right)^{2}+\left(\Delta \mathrm{a}^{*}\right)^{2}}+\left(\Delta \mathrm{b}^{*}\right)^{2}
$$

As médias dos dados de cada um dos onze ensaios para cada resposta foram tratadas por análise de regressão múltipla (Metodologia de Superfície de Resposta), para desenvolver modelos matemáticos de segunda ordem, contendo termos lineares, quadráticos e de interação das duas variáveis independentes, com o emprego do SAS for Windows (THE SAS SYSTEM, 1992).

Com auxílio do programa Statistica (STATISTICA FOR WINDOWS, 2002), os termos não significativos foram retirados, obtendo-se um modelo ajustado mais adequado para descrever os efeitos das variáveis independentes sobre as respostas analisadas. Em alguns casos os termos lineares não significativos $(>0,05 \%)$, estes foram mantidos no modelo (BOX; HUNTER; HUNTER, 1978), pois contribuíram de forma expressiva na resposta analisada. Nos modelos não significativos foram realizados o teste Tukey para comparação das médias entre os experimentos ao nível de 5\% de probabilidade de erro. 


\section{Resultados e Discussão}

As médias dos dados experimentais dos parâmetros instrumentais de cor dos grãos de arroz parboilizados das cvs. BRS Primavera e BRS
Sertaneja estão na Tabela1 e 2 respectivamente. Enquanto a Tabela 3 apresenta as médias dos dados experimentais dos parâmetros instrumentais de cor dos grãos de arroz branco das cvs. BRS Primavera e BRS Sertaneja.

Tabela 1. Médias e desvios-padrão dos parâmetros instrumentais de cor dos grãos da cv. BRS Primavera, em função da temperatura (X1) e tempo de imersão (X2) na etapa de encharcamento da parboilização.

\begin{tabular}{|c|c|c|c|c|c|c|c|c|}
\hline \multirow{3}{*}{ ENSAIO } & \multicolumn{4}{|c|}{$\begin{array}{c}\text { VARIÁVEIS } \\
\text { INDEPENDENTES }\end{array}$} & \multirow{2}{*}{\multicolumn{4}{|c|}{ PARÂMETROS INSTRUMENTAIS DE COR }} \\
\hline & \multicolumn{4}{|c|}{ REAIS CODIFICADAS } & & & & \\
\hline & $\mathrm{X}_{1}$ & $X_{2}$ & $\mathrm{X}_{1}$ & $\mathrm{X}_{2}$ & $\mathrm{~L}^{*}$ & $a^{*}$ & $\mathrm{~b}^{*}$ & $\Delta \mathrm{E}^{*}$ \\
\hline 1 & 60 & 112 & -1 & -1 & $54,06 \pm 0,31$ & $4,55 \pm 0,18$ & $20,61 \pm 0,27$ & $14,79 \pm 0,40$ \\
\hline 2 & 60 & 368 & -1 & 1 & $51,96 \pm 0,65$ & $4,56 \pm 0,34$ & $20,48 \pm 0,36$ & $16,61 \pm 0,80$ \\
\hline 3 & 70 & 112 & 1 & -1 & $52,61 \pm 1,17$ & $4,57 \pm 0,27$ & $20,24 \pm 0,47$ & $15,95 \pm 1,16$ \\
\hline 4 & 70 & 368 & 1 & 1 & $51,68 \pm 0,73$ & $4,41 \pm 0,13$ & $19,72 \pm 0,28$ & $16,58 \pm 0,68$ \\
\hline 5 & 65 & 60 & 0 & $-1,41$ & $54,31 \pm 0,77$ & $4,50 \pm 0,13$ & $21,19 \pm 0,24$ & $14,79 \pm 0,67$ \\
\hline 6 & 65 & 420 & 0 & 1,41 & $52,33 \pm 0,23$ & $4,75 \pm 0,14$ & $20,79 \pm 0,20$ & $16,44 \pm 0,16$ \\
\hline 7 & 58 & 240 & $-1,41$ & 0 & $54,58 \pm 0,25$ & $4,85 \pm 0,11$ & $20,68 \pm 0,20$ & $14,46 \pm 0,14$ \\
\hline 8 & 72 & 240 & 1,41 & 0 & $49,08 \pm 0,72$ & $4,91 \pm 0,04$ & $19,18 \pm 0,28$ & $18,99 \pm 0,64$ \\
\hline 9 & 65 & 240 & 0 & 0 & $52,01 \pm 0,36$ & $4,81 \pm 0,06$ & $20,53 \pm 0,32$ & $16,65 \pm 0,20$ \\
\hline 10 & 65 & 240 & 0 & 0 & $51,93 \pm 0,31$ & $4,87 \pm 0,19$ & $20,72 \pm 0,24$ & $16,80 \pm 0,32$ \\
\hline 11 & 65 & 240 & 0 & 0 & $52,14 \pm 0,61$ & $4,66 \pm 0,18$ & $20,36 \pm 0,11$ & $16,43 \pm 0,59$ \\
\hline
\end{tabular}

L*: luminosidade $(100=$ claro; $0=$ escuro $)$

Coordenadas de cromaticidade: $\mathrm{a}^{*}:(-)$ verde vermelho $(+)$; b*: (-) azul amarelo $(+)$;

$\Delta \mathrm{E}^{*}$ : diferença de cor

Tabela 2. Médias e desvio-padrão dos parâmetros instrumentais de cor dos grãos da cv. BRS Sertaneja, em função da temperatura $\left(\mathrm{X}_{1}\right)$ e tempo de imersão $\left(\mathrm{X}_{2}\right)$ na etapa de encharcamento da parboilização.

\begin{tabular}{|c|c|c|c|c|c|c|c|c|}
\hline \multirow[t]{2}{*}{ ENSAIO } & \multicolumn{4}{|c|}{$\begin{array}{l}\text { VARIÁVEIS } \\
\text { NDEPENDENTES }\end{array}$} & \multicolumn{4}{|c|}{ PARÂMETROS INSTRUMENTAIS DE COR } \\
\hline & $\mathrm{X}_{1}$ & $\mathrm{X}_{2}$ & $\mathrm{X}_{1}$ & $\mathrm{X}_{2}$ & $\mathrm{~L}^{*}$ & $a^{*}$ & $b^{*}$ & $\Delta \mathrm{E}^{*}$ \\
\hline 1 & 60 & 250 & -1 & -1 & $51,24 \pm 0,98$ & $4,26 \pm 0,36$ & $19,95 \pm 0,21$ & $14,79 \pm 0,40$ \\
\hline 2 & 60 & 590 & -1 & 1 & $52,76 \pm 0,57$ & $4,00 \pm 0,03$ & $20,59 \pm 0,08$ & $16,61 \pm 0,80$ \\
\hline 3 & 70 & 250 & 1 & -1 & $49,64 \pm 0,20$ & $4,42 \pm 0,16$ & $19,51 \pm 0,05$ & $15,95 \pm 1,16$ \\
\hline 4 & 70 & 590 & 1 & 1 & $50,82 \pm 0,47$ & $4,10 \pm 0,12$ & $19,50 \pm 0,18$ & $16,58 \pm 0,68$ \\
\hline 5 & 65 & 180 & 0 & $-1,41$ & $52,54 \pm 0,30$ & $4,07 \pm 0,12$ & $20,17 \pm 0,09$ & $14,79 \pm 0,67$ \\
\hline 6 & 65 & 660 & 0 & 1,41 & $51,81 \pm 1,14$ & $3,90 \pm 0,12$ & $19,61 \pm 0,15$ & $16,44 \pm 0,16$ \\
\hline 7 & 58 & 420 & $-1,41$ & 0 & $50,88 \pm 0,29$ & $4,31 \pm 0,12$ & $19,38 \pm 0,22$ & $14,46 \pm 0,14$ \\
\hline 8 & 72 & 420 & 1,41 & 0 & $47,95 \pm 0,40$ & $4,83 \pm 0,16$ & $19,37 \pm 0,15$ & $18,99 \pm 0,64$ \\
\hline 9 & 65 & 420 & 0 & 0 & $51,48 \pm 1,31$ & $4,05 \pm 0,19$ & $20,15 \pm 0,24$ & $16,65 \pm 0,20$ \\
\hline 10 & 65 & 420 & 0 & 0 & $52,35 \pm 0,31$ & $3,83 \pm 0,18$ & $19,84 \pm 0,04$ & $16,80 \pm 0,32$ \\
\hline 11 & 65 & 420 & 0 & 0 & $51,20 \pm 0,82$ & $4,16 \pm 0,19$ & $19,59 \pm 0,22$ & $16,43 \pm 0,59$ \\
\hline
\end{tabular}

L*: luminosidade $(100=$ claro; $0=$ escuro $)$;

coordenadas de cromaticidade: $\mathrm{a}^{*}$ : (-) verde vermelho $(+)$ e $\mathrm{b}^{*}:(-)$ azul amarelo (+);

$\Delta \mathrm{E}^{*}$ : diferença de cor 
Tabela 3. Médias e desvios-padrão dos parâmetros instrumentais de cor dos grãos de arroz branco das cvs. BRS Primavera e BRS Sertaneja.

\begin{tabular}{llll}
\hline \multirow{2}{*}{ CULTIVAR } & \multicolumn{3}{l}{ PARÂMETROS INSTRUMENTAIS DE COR } \\
\cline { 2 - 4 } & $\mathrm{L}^{*}$ & $\mathrm{a}^{*}$ & $\mathrm{~b}^{*}$ \\
\hline BRS Primavera & 66,93 & 0,04 & 14,9 \\
BRS Sertaneja & 69,28 & $-0,51$ & 13,36 \\
\hline
\end{tabular}

$\mathrm{L}^{*}$ : luminosidade $(100=$ claro; $0=$ escuro);

Coordenadas de cromaticidade: $\mathrm{a}^{*}:(-)$ verde vermelho (+) e b*: (-) azul amarelo (+);

$\Delta \mathrm{E}^{*}$ : diferença de cor

A luminosidade $\left(\mathrm{L}^{*}\right)$ dá uma idéia de intensidade que vai do preto ("escuro") ao branco ("claro"), numa escala arbitrária de 0 até 100 , respectivamente. A luminosidade é um atributo de qualidade do arroz que esta relacionado com a cultura dos consumidores. Normalmente, o arroz parboilizado possui "cor mais escura” que o não parboilizado, o que pode ser observado também neste trabalho (Tabelas 1, 2 e 3). Em geral, nos continentes americano e europeu o arroz mais claro é mais preferido, assim pesquisadores destes continentes procuram técnicas que possibilitem a reprodução desse padrão no arroz parboilizado (LAMBERTS et al., 2008).

A Tabela 4 mostra os modelos de regressão ajustados e os coeficientes de determinação $\left(\mathrm{R}^{2}\right)$ para essas respostas. Para a cv. BRS Primavera o modelo completo para $\mathrm{L}^{*}$ não foi significativo $(\mathrm{P}=$ $0,0758)$, mas o efeito linear da variável temperatura foi significativo $(\mathrm{P}=0,0176)$. $\mathrm{O}$ efeito linear do tempo de imersão apesar de não ser significativo $(\mathrm{P}=0,0848)$, contribuiu expressivamente para a resposta. O C.V. foi baixo $(1,84 \%)$ e falta de ajuste significativa $(\mathrm{FA}=0,007)$, porém o quadrado médio do erro experimental foi baixo $(0,0112)$, podendo o modelo ser utilizado para verificação da tendência da resposta. $\mathrm{O}$ modelo de regressão de L* para a cv. BRS Sertaneja foi significativo (P $=0,0351)$, com C.V. $(1,4 \%)$ baixo e falta de ajuste não significativa $(\mathrm{FA}=0,37)$, podendo ser usado com fins preditivos dentro da região estudada. Os termos que influenciaram a $\mathrm{L}^{*}$ foram os efeitos linear e quadrático da temperatura utilizada no encharcamento. Os modelos ajustados (Tabela 4) são significativos, mas a cv. BRS Primavera apresentou o $\mathrm{R}^{2}$ baixo, que explica apenas $57,7 \%$ e a cv. BRS Sertaneja apresentou $\mathrm{R}^{2}$ igual a $80,4 \%$.

Com os modelos ajustado para $L^{*}$ foram elaborados gráficos de curvas de nível e de regressão simples, que mostram a variação da resposta em função da temperatura da água e do tempo imersão, e somente da temperatura da água para as cultivares BRS Primavera e BRS Sertaneja, respectivamente, conforme observado na (Figura 1). 
Tabela 4. Modelos de regressão ajustados e coeficientes de determinação $\left(\mathrm{R}^{2}\right)$ dos parâmetros instrumentais de cor dos grãos da cvs. BRS Primavera e BRS Sertaneja, em função da temperatura $\left(\mathrm{x}_{1}\right)$ e tempo de imersão $\left(\mathrm{x}_{2}\right)$ na etapa de encharcamento da parboilização.

\begin{tabular}{cc}
\hline PARÂMETROS & \\
$\begin{array}{c}\text { INSTRUMENTAIS DE } \\
\text { COR }\end{array}$ & MODELO AJUSTADO \\
\hline
\end{tabular}

$\begin{array}{lcc} & \text { BRS Primavera } & \\ \mathrm{L}^{*} & \mathrm{y}_{\mathrm{i}}=52,4261-1,1888 \mathrm{x}_{1}-0,7319 x_{2} & 57,75 \\ \mathrm{a}^{*} & - & - \\ \mathrm{b}^{*} & \mathrm{y}_{\mathrm{i}}=20,7058-0,4077 \mathrm{x}_{1}-0,4129 \mathrm{x}_{1}{ }^{2} & 77,83 \\ \Delta \mathrm{E}^{*} & \mathrm{y}_{\mathrm{i}}=16,2254+0,9446 \mathrm{x}_{1} & 44,57 \\ & \text { BRS Sertaneja } & 80,42 \\ & \mathrm{y}_{\mathrm{i}}=51,9899-0,9651 \mathrm{x}_{1}-1,1632 \mathrm{x}_{1}{ }^{2} & 77,43 \\ \mathrm{~L}^{*} & \mathrm{y}_{\mathrm{i}}=3,9816+0,1252 \mathrm{x}_{1}+0,2697 \mathrm{x}_{1}{ }^{2}-0,1026 x_{2} & - \\ \mathrm{a}^{*} & - & 80,91 \\ \mathrm{~b}^{*} & \mathrm{y}_{\mathrm{i}}=19,0436+0,8535 \mathrm{x}_{1}+1,0694 \mathrm{x}_{1}{ }^{2} & \end{array}$

$y_{1}=$ resposta; $x_{1}=$ temperatura $\left({ }^{\circ} \mathrm{C}\right) ; x_{2}=$ tempo de imersão $(\mathrm{min}) ; \mathrm{L}^{*}:$ luminosidade $(100=$ claro; $0=$ escuro $)$, coordenadas de cromaticidade: $\mathrm{a}^{*}:(-)$ verde vermelho $(+)$ e $\mathrm{b}^{*}:(-)$ azul amarelo $(+) ; \Delta \mathrm{E}^{*}$ : diferença de cor; $* \mathrm{P} \leq 0,05$ (nível de probabilidade pelo teste F); itálico: o efeito apesar de não ser significativo ao nível de $5 \%$, contribuiu com a resposta.

(a)

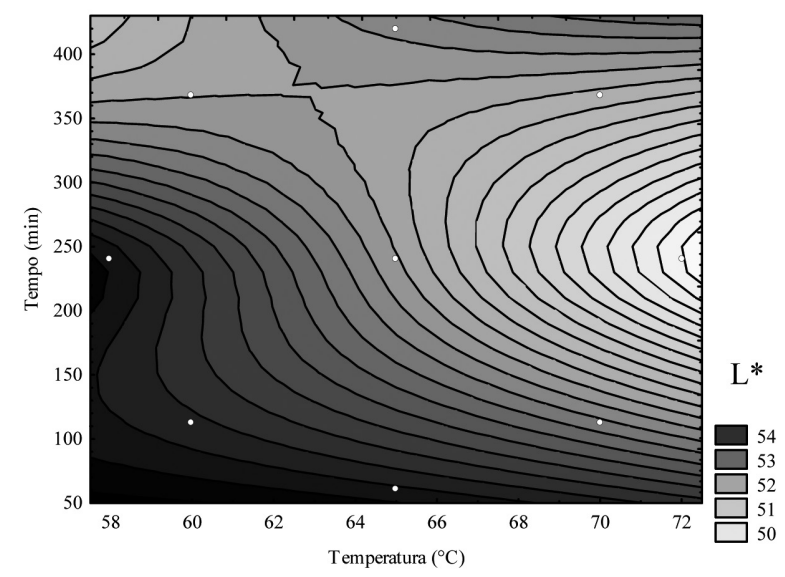

(b)

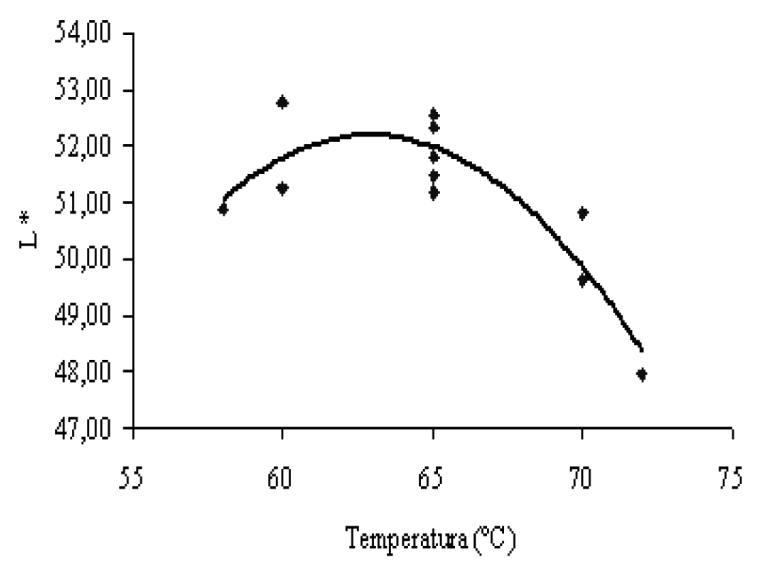

Figura 1. Efeito da temperatura e tempo de imersão na etapa de encharcamento da parboilização sobre a luminosidade L* do grão das cvs. BRS Primavera (a) e BRS Sertaneja (b). 
A região ideal (grãos mais claros, ou seja, valores mais próximos de 100) com relação ao parâmetro L* dos grãos parboilizados para a cv. BRS Primavera, encontra-se nas faixas de temperatura entre $58{ }^{\circ} \mathrm{C}$ - $60{ }^{\circ} \mathrm{C}$ com tempos de imersão abaixo de 240 min e entre $60{ }^{\circ} \mathrm{C}-72{ }^{\circ} \mathrm{C}$ com tempos de imersão abaixo de 112 min. Pode-se observar nas faixas citadas que a medida que se aumenta a temperatura é necessário diminuir o tempo de imersão para obter grãos mais claros, ou seja, condições brandas de encharcamento, geram produtos mais claros. O efeito mais importante é a temperatura, pois pode ocorrer o splitting mais intenso acima de 70 ${ }^{\circ} \mathrm{C}$, com consequente absorção pelo endosperma dos pigmentos da casca, dissolvidos na água de encharcamento (BHATTACHARYA, 1986; GARIBOLDI, 1974).

Para a luminosidade dos grãos da cv. BRS Sertaneja, pode-se observar que as condições de encharcamento que utilizaram temperaturas mais elevadas $\left(>70^{\circ} \mathrm{C}\right)$ produziram grãos mais escuros (menor valor de $\mathrm{L}^{*}$ ) e em temperaturas mais baixas $\left(<65^{\circ} \mathrm{C}\right.$ ), grãos mais claros (maior valor de $\mathrm{L}^{*}$ ). Quando a temperatura de encharcamento permanece acima da temperatura de gelatinização $\left(69^{\circ} \mathrm{C}-73\right.$ $\left.{ }^{\circ} \mathrm{C}\right)$ (MARTINÉZ; CUEVAS, 1989), a abertura da casca tende a ser mais intensa, pois a hidratação é mais rápida e a quantidade de água absorvida pelo grão é maior. Consequentemente, ocorre maior absorção pelo endosperma dos pigmentos da casca e da camada do farelo, lixiviados para a água de maceração (BHATTACHARYA, 1986; GARIBOLDI, 1974), e também há migração de componentes da camada interna (lipídios) para a superfície do grão (LAMBERTS et al., 2006b), escurecendo dessa forma o grão (BHATTACHARYA, 1986).

As médias de $\mathrm{L}^{*}$ obtidas para as cvs. BRS Primavera (entre 49,1 e 54,3) e BRS Sertaneja (de 47,9 a 52,8) estão abaixo dos valores relatados por Amato, Carvalho e Silveira Filho (2002), que variaram entre 57,4 a 58,5. Lamberts et al. (2006b) analisaram a cor do grão de arroz para a cultivar
Puntal após o encharcamento ( $25-30 \%$ de umidade) a temperatura ambiente, e os valores encontrados por estes autores variaram de 77,7 - 78,4, ou seja, grãos mais claros que os encontrados neste trabalho, pois as amostras não foram submetidas a etapa de autoclavagem que, segundo Amato et al. (1990), contribui com a cor do arroz parboilizado, porém, com menor hierarquia de importância que a etapa de encharcamento.

Estes resultados comprovam que o aumento da temperatura acelera a absorção de água, e o grão estando completamente saturado, adquire colorações mais escuras, principalmente quando é ultrapassado o limite de $70{ }^{\circ} \mathrm{C}$, devido a abertura da casca e a consequente absorção de pigmentos. Além do mais, durante o encharcamento, as enzimas presentes tanto nas camadas externas quanto no endosperma do arroz são ativadas, favorecendo a hidrólise do amido com a produção de açúcares redutores, especialmente glucose. Ao aumentar o teor de açúcares, criam-se condições para a reação de escurecimento não enzimática do tipo Maillard, ocorrendo uma tendência à acentuação da coloração típica do parboilizado (BHATTACHARYA; SUBBA RAO, 1966).

As amostras de arroz parboilizado acusam leituras de a* próximas de quatro (Tabelas 1 e 2), ou seja, pouco acima do padrão para arroz branco, que é próximo de zero (Tabela 3). O interesse deste parâmetro para o arroz seria para identificar e quantificar a intensidade da cor de grãos imaturos, cujos resultados dariam menor que zero, indicando uma tendência ao verde. Serviria também para avaliar a intensidade de amostras de arroz vermelho, na escala positiva (AMATO; CARVALHO; SILVEIRA FILHO, 2002).

A cv. BRS Primavera apresentou modelo para a coordenada de cromaticidade $\mathrm{a}^{*}$ não significativo (P $=0,63)$, com $\mathrm{R}^{2}$ de $42,5 \%$, C.V. baixo $(3,9 \%)$ e falta de ajuste não significativa $(\mathrm{FA}=0,20)$, indicando que o modelo não se ajusta aos dados experimentais. A coordenada de cromaticidade a* não apresentou 
diferença significativa entre os experimentos pelo teste Tukey a 5\% de probabilidade de erro. O modelo para a coordenada de cromaticidade $a^{*}$ para a cv. BRS Sertaneja foi significativo $(0,037)$, com C.V. baixo $(3,6 \%)$ e falta de ajuste não foi significativa $(\mathrm{FA}=0,66) . \mathrm{O}^{2}$ do modelo completo foi de $85,6 \%$, sendo reduzido para $77,4 \%$ no modelo ajustado (Tabela 4). Os efeitos linear e quadrático da temperatura foram significativos para a resposta estudada e o tempo de imersão contribuiu expressivamente para a resposta, apesar de não ser significativo $(P=0,06)$. A partir do modelo ajustado para a cultivar BRS Sertaneja foi construído gráfico de curvas de nível para a variável estudada (Figura 2).

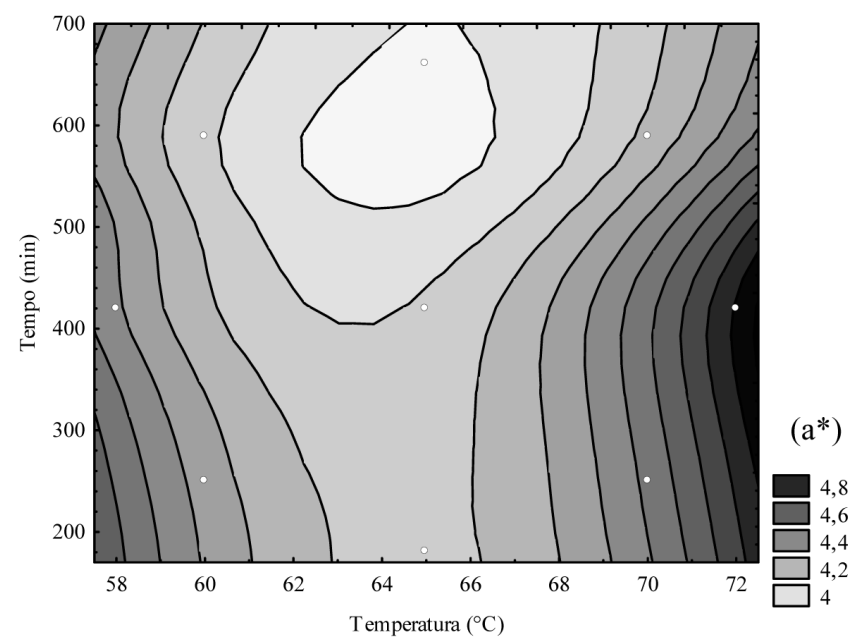

Figura 2. Efeito da temperatura e do tempo de imersão do encharcamento da parboilização sobre a coordenada de cromaticidade a* da cv. BRS Sertaneja

Nota-se no gráfico da Figura 2, que a região da coordenada de cromaticidade a* com os menores valores (mais próximos de zero), ou seja, menos avermelhados estão na faixa de temperatura de 62 ${ }^{\circ} \mathrm{C}-66{ }^{\circ} \mathrm{C}$ e tempos de imersão entre $500 \mathrm{~min}-$ $660 \mathrm{~min}$. Verifica-se que na temperatura de 72 ${ }^{\circ} \mathrm{C}$ e tempos de imersão entre $180 \mathrm{~min}-490 \mathrm{~min}$ foram os que apresentaram os valores de $\mathrm{a}^{*}$ mais elevados (grãos mais avermelhados). As condições mais extremas de temperatura são capazes de dissolver certas substâncias presentes no grão de arroz e contribuir para o pequeno aumento do valor de a* nestas regiões. Verifica-se com os resultados obtidos que as cultivares apresentaram valores muito próximos para a coordenada $a^{*}$, dando leituras próximas de zero, ou seja, menos verdes e menos vermelhas. Os resultados encontrados neste trabalho estão um pouco acima dos relatos por Amato, Carvalho e Silveira Filho (2002), que variaram de 2,3-2,7.

O parâmetro $b^{*}$ é o mais importante para acompanhamento da cor típica do arroz parboilizado, principalmente na parte positiva da escala, cujos valores crescentes indicam a maior participação do amarelo, ao passo que a escala negativa, identificando tons de azul, que serviria, só para avaliar a intensidade de colônia de alguns mofos (AMATO; CARVALHO; SILVEIRA FILHO, 2002). Os valores de b* dos grão brancos das duas cultivares estudadas foram próximos de $14 \%$ (Tabela 3), enquanto dos grãos parboilizados ficaram ao redor de $20 \%$ (Tabelas 1 e 2 ).

O modelo completo para a coordenada de cromaticidade $b^{*}$ da cultivar BRS Primavera foi significativo ( $\mathrm{P}=0,01)$, com C.V baixo $1,1 \%), \mathrm{R}^{2}$ de $91,2 \%$, sendo reduzido para $77,8 \%$ para o modelo 
ajustado. A falta de ajuste não foi significativa $(\mathrm{FA}=0,35)$ podendo o modelo ser usado com fins preditivos. Os efeitos linear e quadrático da temperatura foram significativos. Para a cv. BRS Sertaneja, o modelo não foi significativo $(\mathrm{P}=$ 0,57). Com o modelo ajustado para a cultivar BRS Primavera, foi construído gráfico de regressão simples, conforme a Figura 3, que pode-se verificar o efeito da temperatura sobre a coordenada $b^{*}$.

$\mathrm{Na}$ Figura 3 pode-se observar que nas temperaturas entre $58{ }^{\circ} \mathrm{C}-65^{\circ} \mathrm{C}$, onde o processo de hidratação é mais lento, o tempo necessário para a cariopse atingir 30\% de umidade é maior. Nessas condições, certas substâncias presentes no arroz podem se dissolver na água e a semente pode começar a germinar (se houver ar dissolvido na água). Além de favorecer as fermentações, ocasionando alteração na cor e possivelmente aumentar o valor de $b^{*}$ nesta faixa de temperatura. Já na faixa de temperatura de $65{ }^{\circ} \mathrm{C}-72{ }^{\circ} \mathrm{C}$ o valor de $b^{*}$ diminui. Este fato também foi observado por Lamberts et al. (2006a), porém esses analisaram a cor da farinha de grãos encharcados em temperaturas de $40{ }^{\circ} \mathrm{C}$ e 65 ${ }^{\circ} \mathrm{C}$ e tempos de imersão de 10, 30, 60, 120 e 300 min. Esses autores afirmaram que esta mudança de cor poderia ser explicada pela diferença na taxa de absorção de água e na lixiviação do material em diferentes temperaturas. Portanto, nas temperaturas de encharcamento mais elevadas o máximo de absorção de água é obtido, consequentemente, maior teor de material é lixiviado, elevando as perdas de constituintes (pigmentos amarelos presentes na camada do farelo), que agregam coloração amarela ao grão. No entanto, apesar do efeito significativo da temperatura sobre a coordenada de cromaticidade $b^{*}$, a variação numérica ocorrida (Tabela 2) foi muito pequena, entre 19,2- 21,2, variação pouco representativa na percepção da cor amarela pelo olho humano.

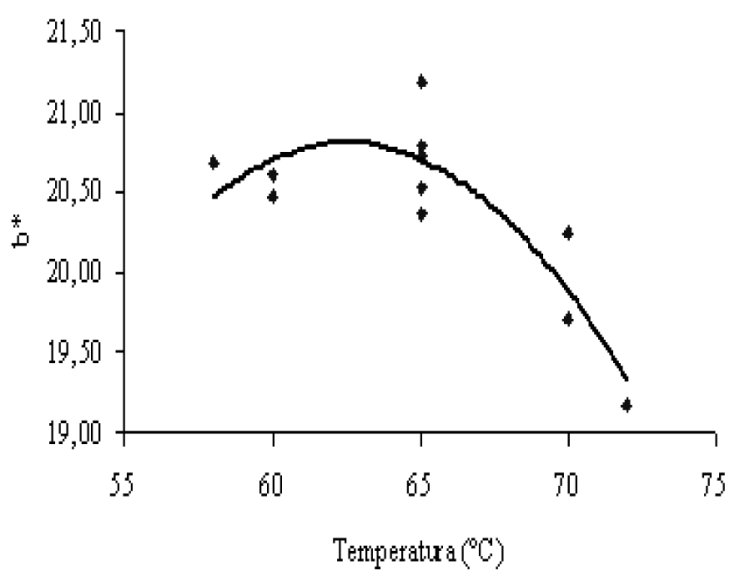

Figura 3. Efeito da temperatura do encharcamento da parboilização sobre a coordenada $b^{*}$ da cv. BRS Primavera.

Para a cv. BRS Sertaneja, os valores de b* variaram entre 19,2 - 20,8, variação pouco representativa na percepção da cor amarela pelo olho humano. Segundo a literatura, os resultados encontrados para as amostras de arroz parboilizado, encontram-se próximas de +19 , pela cor típica do arroz parboilizado, algo amarelada (AMATO;
CARVALHO; SILVEIRA FILHO, 2002), sendo que estes resultados estão próximos dos encontrados.

A diferença de cor $\left(\Delta \mathrm{E}^{*}\right)$ é uma conjugação das contribuições dos demais parâmetros, dando uma idéia da cor por meio de um número (AMATO; CARVALHO; SILVEIRA FILHO, 2002). A Anova para a cv. BRS Primavera mostrou que o modelo 
completo não foi significativo $(\mathrm{P}=0,11)$ mas $\mathrm{o}$ efeito linear da variável temperatura foi significativo $(\mathrm{P}=0,03)$. $\mathrm{O}$ modelo ajustado é significativo, mas apresenta $\mathrm{R}^{2}$ baixo, que explica apenas $44,57 \%$ das respostas, servindo somente para verificar a tendência das respostas (Tabela 4). O modelo de regressão de $\Delta \mathrm{E}^{*}$ para a cv. BRS Sertaneja foi significativo $(\mathrm{P}=0,03)$, com o C.V. baixo $(3,3 \%)$, a falta de ajuste não significativa $(\mathrm{FA}=0,44)$, o $\mathrm{R}^{2}$ do modelo completo igual a $86,4 \%$, sendo reduzido para $80,9 \%$ no modelo ajustado, podendo ser usado com fins preditivos, dentro da região estudada. Os termos que influenciaram significativamente a $\Delta \mathrm{E}^{*}$ foram os efeitos linear e quadrático da temperatura

(a)

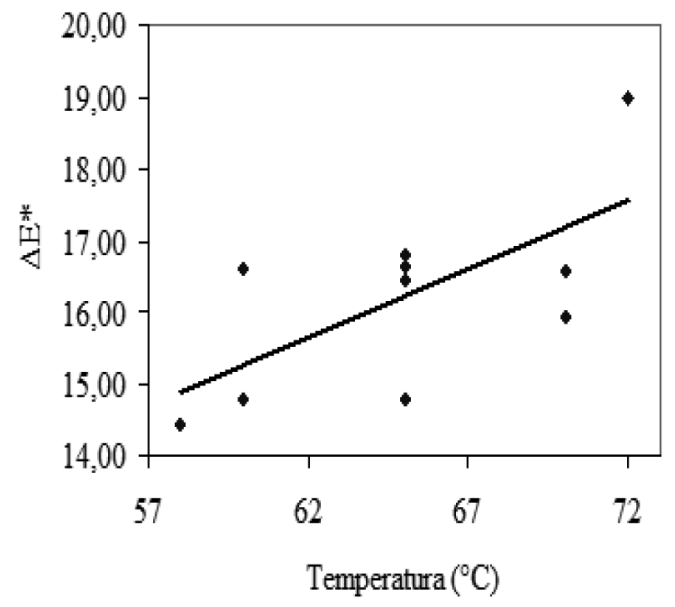

utilizada no encharcamento. Com os modelos ajustados (Tabela 4) foram elaborados gráficos de regressão, que mostra a variação de $\Delta \mathrm{E}^{*}$ em função da temperatura (Figura 4).

Verifica-se na Figura 4 que existe uma tendência em aumentar a diferença de cor existente entre as amostras de arroz parboilizado e a de arroz branco a medida que aumenta a temperatura. Esse fato é de se esperar uma vez que é inerente ao processo de parboilização a agregação de coloração, a ponto da legislação nacional vigente reconhecer esta característica, em decorrência do tratamento hidrotérmico (AMATO et al., 1990).

Figura 4. Efeito da temperatura do encharcamento da parboilização sobre a diferença de cor do grão $\left(\Delta \mathrm{E}^{*}\right)$ das cvs. BRS Primavera (a) e BRS Sertaneja (b)

A cv. BRS Sertaneja apresentou uma redução de $\Delta \mathrm{E}^{*}$ na faixa de temperatura entre $58-63{ }^{\circ} \mathrm{C}$ (região ideal para obtenção de um produto mais semelhante ao arroz branco). A partir de $63{ }^{\circ} \mathrm{Co} \Delta \mathrm{E}^{*}$ começou a aumentar com a elevação da temperatura da água de imersão. Este resultado é de se esperar uma vez que em baixas temperaturas, o efeito de abertura da casca é menos intenso e consequentemente a absorção pelo endosperma dos pigmentos dissolvidos da casca também é menor (BHATTACHARYA, 1986).

$\mathrm{O}$ arroz branco da cv. BRS Primavera foi mais claro, avermelhado e amarelado que o da cv. BRS Sertaneja. Após a parboilização sob diferentes condições de temperatura e tempo de encharcamento esta tendência permaneceu, mas a variação de cor $\left(\Delta \mathrm{E}^{*}\right)$ foi maior na $\mathrm{cv}$. BRS Sertaneja. 


\section{Conclusões}

A temperatura da água na etapa de encharcamento do processo de parboilização afetou a luminosidade, a coordenada de cromaticidade $b^{*}$ e a diferença de cor dos grão da cultivar BRS Primavera, enquanto o tempo de encharcamento somente a coordenada de cromaticidade $\mathrm{a}^{*}$.

A temperatura da água na etapa de encharcamento da parboilização afetou a luminosidade, a coordenada de cromaticidade $a^{*}$ e a diferença de cor dos grão da cultivar BRS Sertaneja, enquanto o tempo de encharcamento somente a luminosidade.

Nas condições extremas do encharcamento (principalmente em temperaturas elevadas) observou-se, que os grãos de arroz parboilizado apresentaram cores mais escuras, amareladas e avermelhadas que as amostras dos grãos de arroz branco.

O arroz branco da cv. BRS Primavera é mais claro, avermelhado e amarelado que o da cv. BRS Sertaneja. Após a parboilização sob diferentes condições de temperatura e tempo de encharcamento esta tendência permanece, mas a variação de cor $\left(\Delta \mathrm{E}^{*}\right)$ é maior na cv. BRS Sertaneja.

Pode-se produzir grãos com diferentes tonalidades, dependendo das condições de processamento utilizadas e respostas semelhantes são obtidas em diferentes combinações entre temperatura e tempo de encharcamento. A escolha vai depender da aplicação a que se destina ou dos produtos em que serão empregados.

\section{Agradecimentos}

À Empresa Brasileira de Pesquisa Agropecuária Arroz e Feijão, de Santo Antônio de Goiás-GO, pelo suporte técnico e apoio financeiro e à Coordenação de Aperfeiçoamento de Pessoal de Nível Superior (CAPES), pela concessão de bolsa de mestrado.

\section{Referências}

ALI, S. Z.; BHATTACHARYA, K. R. Starch retrogradation and starch damage in parboiled rice and flaked rice. Starch/Stärke, Weinheim, v. 28, n. 2, p. 233240, 1976.

AMATO, G. W.; CARVALHO, J. L. V.; SILVEIRA FILHO, S. Arroz parboilizado: tecnologia limpa, produto nobre. Porto Alegre: Ricardo Lenz, 2002. 240 p.

AMATO, G. W.; ELIAS, M. C. A parboilização do arroz. Porto Alegre: Ricardo Lenz, 2005. 160 p.

AMATO, G. W.; PINKOSKI, P. I.; OLIVERAS, L. Y.; PFINGSTAG, R.; GUNDANI, C. Cor na parboilização do arroz. Porto Alegre: CIENTEC, 1990. 39 p. (Boletim Técnico, 19).

AMATO, G. W.; SILVEIRA FILHO, S. Arroz parboilizado: uma recomendação da FAO e OMS. Porto Alegre: CIENTEC, 1995. 23 p. (Boletim Técnico, 13).

BASSINELLO, P. Z.; CASTRO, E. M. Arroz como alimento. Informe Agropecuário, Belo Horizonte, v. 25, n. 222, p. 101-108, 2004.

BHATTACHARYA, K. R. Parboiling of rice . In: JULIANO, B. O. (Ed.). Rice: chemistry and technology. St. Paul, American Association of Cereal Chemistry, 1986. cap. 8, p. 289-348.

BHATTACHARYA, K. R.; SUBBA RAO, P. V. Effect of processing conditions on quality of parboiled rice. Journal of Agricultural and Food Chemistry, Easton, v. 14, n. 5, p. 476-479, 1966.

BOX, G. E. P.; HUNTER, W. G.; HUNTER, J. S. Statistics for experimenters. New York: John Wiley \& Sons, 1978. $653 \mathrm{p}$.

BRESEGHELLO, F.; CASTRO, E. M.; MORAIS, O. P. Cultivares de arroz. In: BRESEGHELLO, F.; STONE, L. F. (Ed.). Tecnologia para o arroz de terras altas. Santo Antônio de Goiás: Embrapa Arroz e Feijão, 1998. 161 p.

CHOUDHURY, N. H. Parboiling and consumer demand of parboiled rice in south Asia. In: JULIANO, B. O.; POLLARD, L. R.; ARGOSINO, G. (Ed.). Rice grain marketing and quality issues. Manila: International Rice Research Institute, 1991. cap. 4, p. 47-54.

DILLAHUNTY, A. L.; SIEBENMORGEN, T. J.; MAUROMOUSTAKOS, A. Effect of temperature, exposure duration, and moisture content on color and viscosity of rice. Cereal Chemistry, Saint Paul, v. 78, n. 5, p. 559-563, 2001. 
ELIAS, M. C. Tempo de espera para secagem e qualidade de arroz para semente e indústria. 1998. Tese (Doutorado em Ciência e Tecnologia de Sementes) Faculdade de Agronomia Eliseu Maciel. Universidade Federal de Pelotas, Pelotas.

FERREIRA, E. V. O; CARVALHO, J. G.; FARIA, L. A. J.; BASTOS, A. R. R.; PINHO, P. J. Manganês na nutrição mineral de cultivares de arroz de terras altas. Pesquisa Agropecuária Tropical, v. 39, n. 2, p. 151-157, abr./jun. 2009.

FONSECA, H.; SOAVE, J.; AZZINI, L. E.; BANZATTO, N. V.; CAMARGO, O. B. A. Arroz: produção, préprocessamento e transformação agroindustrial. São Paulo: EDUSP, 1983. 528 p.

GARIBOLDI, F. Rice parboiling. Rome: Food and Agricultural Organization of the United Nations, 1974. 97 p. (FAO Agricultural Development Paper, 97).

GUIMARÃES, C. M.; STONE, L. F. Arroz de terras altas em rotação com soja. Pesquisa Agropecuária Tropical, Goiânia, v. 34, n. 3, p. 127-132, 2004.

HEINEMANN, R. J. B.; BEHRENS, J. H.; LANFERMARQUEZ, U. M. A study on the acceptability and consumer attitude towards parboiled rice. International Journal of Food Science and Technology, Oxford, v. 41, n. 6, p. 627-634, 2006.

LAMBERTS, L.; BRIJS, K.; MOHAMED, R.; VERHELST, N.; DELCOUR, J. A. Impact of browning reactions and bran pigments on color of parboiled rice. Journal of Agriculture and Food Chemistry, Easton, v. 54, n. 26, p. 9924-9929, 2006a.

LAMBERTS, L.; DE-BIE, E.; DERYCKE, V.; VERAVERBEKE, W. S.; DE-MAN, W.; DELCOUR,
J. A. Effect of processing conditions on color change of brown and milled parboiled rice. Cereal Chemistry, Saint Paul, v. 83, n. 1, p. 80-85, 2006b.

LAMBERTS, L.; ROMBOUTS, I.; BRIJS, K.; GEBRUERS, K.; DELCOUR, J. A. Impact of parboiling conditions on Maillard precursors and indicators in longgrain rice cultivars. Journal of Food Chemistry, London, v. 110, n. 4, p. 916-922, 2008.

MARTINÉZ, C.; CUEVAS, F. Evaluación de la calidad culinária y molinera del arroz: guia de estúdio para ser usada como complemento de la unidad auditutorial sobre el mismo tema. 3. ed. Cali: Centro Internacional de Agricultura Tropical, 1989. 73 p.

MINOLTA. Precise color communication: color control from feeling to instrumentation. Japão: Minolta Co., Ltd., 1994. 49 p.

RODRIGUES, M. I.; IEMMA, A. F. Planejamento de experimentos e otimização de processos: uma estratégia seqüencial de planejamentos. Campinas: Casa do Pão Editora, 2005. 326 p.

SRIDHAR, B. S.; MANOHAR, B. Hydration kinetics and energy analysis of parboiling indica paddy. Biosystems Engineering, London, v. 85, n. 2, p. 173-183, 2003.

STATISTICA for Windows (2002) Software.Version 6: Statsoft, Tulsa, OK, USA, 2002. v. 2. (Licenciado n. 1101).

THE SAS SYSTEM for Windows 3.95 - Release 6.08. SAS Institute, Inc. Cary, NC, USA, 1992.

VIEIRA, N. R. de. A. Qualidade de grãos e padrões de classificação de arroz. Informe Agropecuário, Belo Horizonte, v. 25, n. 222, p. 94-100, 2004. 